\title{
HEALTH QUALITY PROGNOSTIC FACTORS IN PATIENTS WITH ATHEROTHROMBOTIC STROKE
}

Pavlov University

\section{First Saint-Petersburg I.P. Pavlov State Medical University, Saint-Petersburg}

Purpose

Our study's goal was to investigate health quality prognostic factors in patients with atherothrombotic stroke due to atherosclerotic carotid stenosis (ACAS).

\section{Methods}

Insulin-like growth protein (IGF) family and non-lipid atherosclerosis biomarkers serum levels were measured in 75 patients with acute atherothrombotic stroke with $50-99 \%$ ACAS, 25 patients with severe ACAS with history of stroke during more then 2 month before study entry, 24 patients with ACAS without history of stroke or TIA and 24 healthy volunteers. Age range was 50-80 years. European Quality of Life Questionnaire (EQ-5D) and EQ-5D visual analogue scale (VAS) were performed at 90 days from enrollment.

Inclusion criteria:

- Age range 50-80 years

Patients with ACAS
Control group

- IMT $<0,9 \mathrm{~cm}$

- without history of stroke or TIA
- Informed consent

NASCET

Exclusion criteria:

Non-atherothrombotic stroke risk factors [TOAST].

Diabetes mellitus.

Chronic diseases decompensation.

Infections, acute diseases (myocardial infraction, unstable angina, pulmonary artery thromboembolia).

Big surgery during 1 month from inclusion, history of carotid artery or brain surgery.

Neurodegenerative diseases or other neurologic impairment reasons.

MMSE $<20$

Neuroprotective drugs intake during 1 week before study enrollment.

Cancer, hematologic malignancy.

Anemia (hemoglobin $<100 \mathrm{~g} / \mathrm{l}$ ) or blood transfusion during 1 month before study enrollment.

Pregnancy or birth during 1 year before study enrollment.
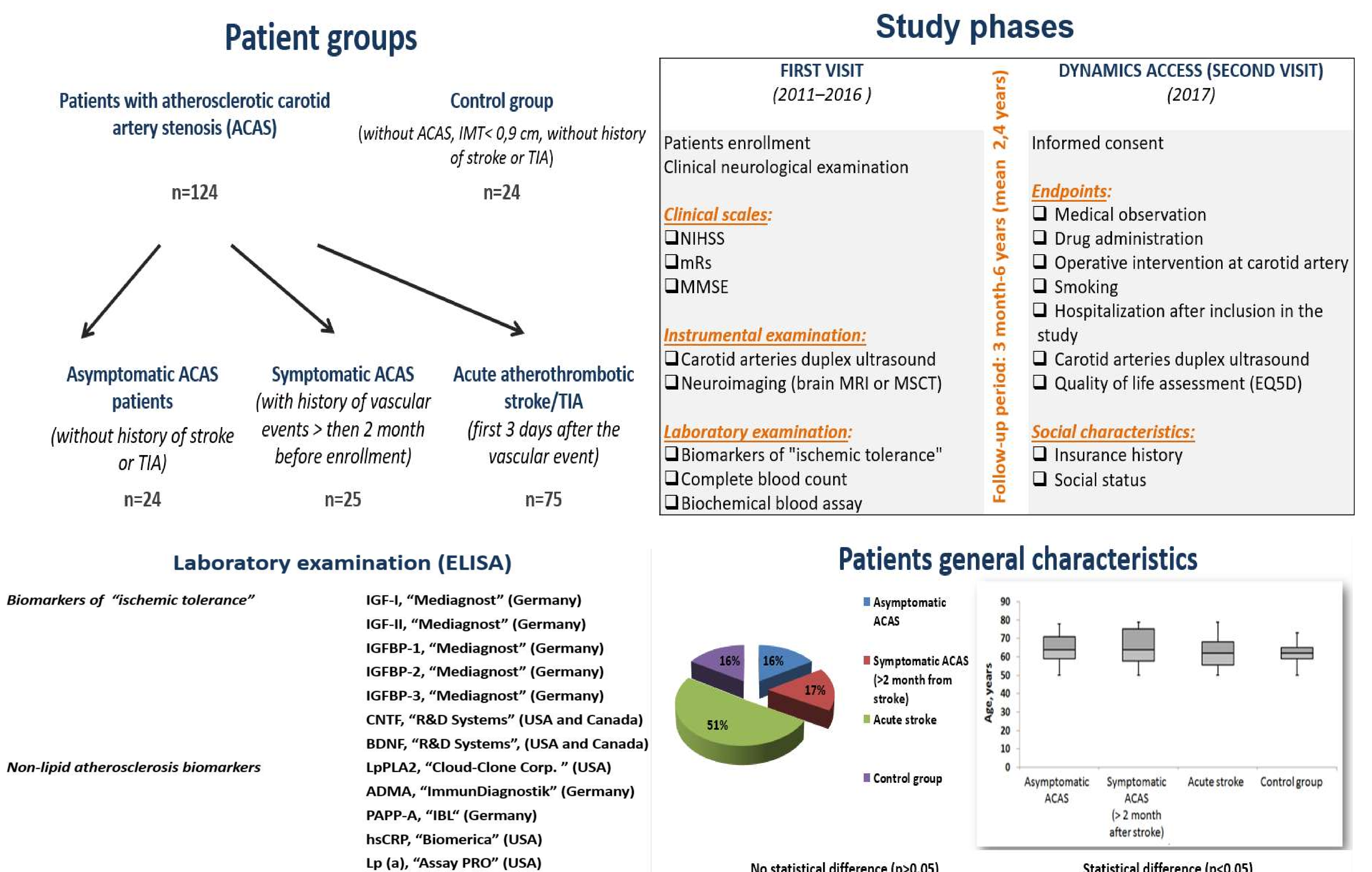

tatistical analysis (SPSS 20,0)

$\begin{array}{lll}\begin{array}{l}\text { Independent samples access } \\ \text { Qualitative variables }\end{array} & -\begin{array}{l}\text { Kruskal-Wallis and Mann- } \\ \text { Whitney test (2 sided) } \\ \text { comparison } \\ \text { Variables relationship }\end{array} & -\quad \begin{array}{l}\text { Kearson's chi-square test } \\ \text { cendall tau rank }\end{array} \\ \text { Risk analysis } & - & \begin{array}{l}\text { Crostation coefficient } \\ \text { Crobles, odds ratio }\end{array}\end{array}$

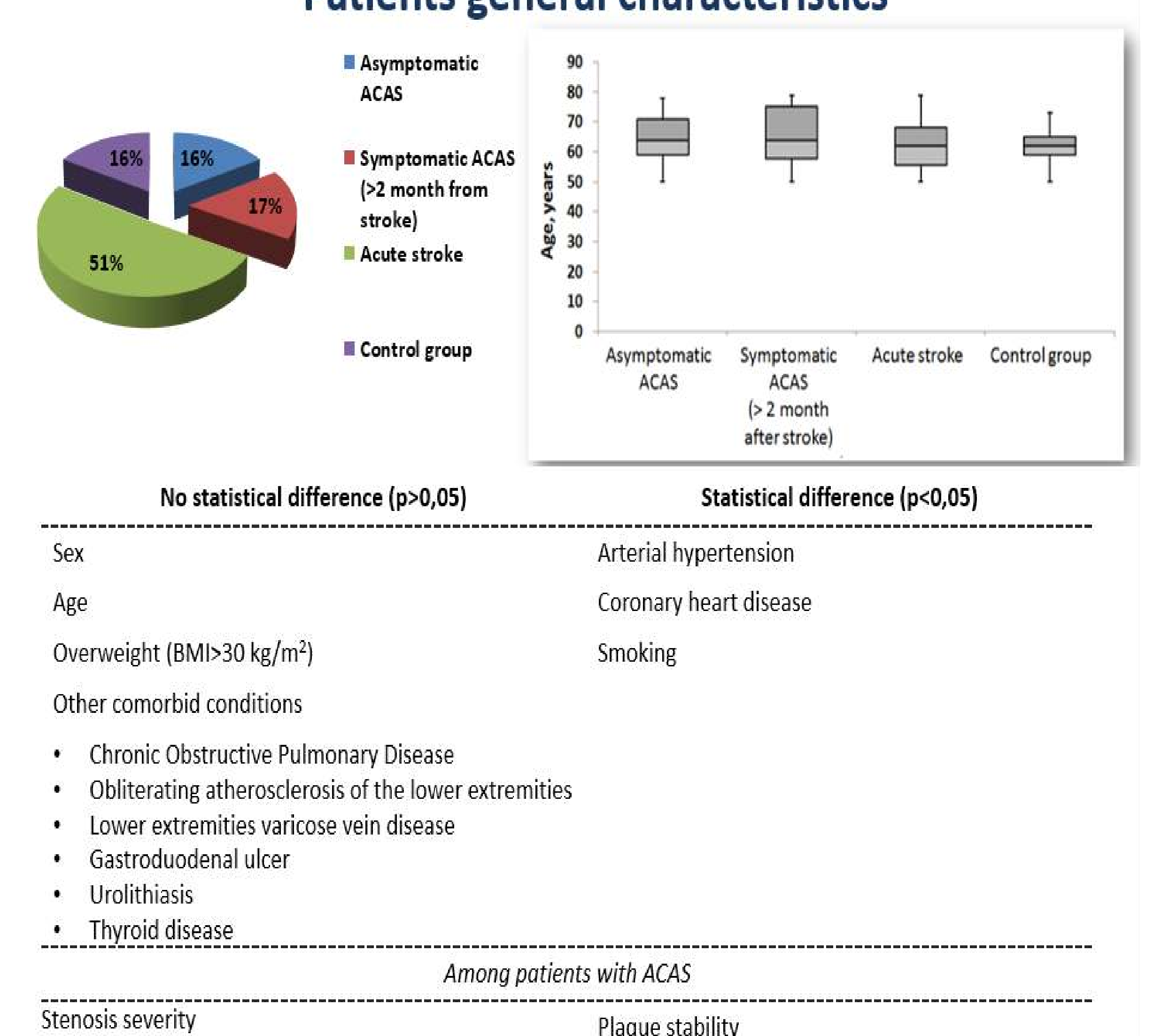

Results

In patients with ACAS mRs and NIHSS levels increase and MMSE levels decrease were associated with total EQ-5D-score increase $(T=0,635, p<0,001 ; T=0,377$, $\mathrm{p}<0,001 ; \mathrm{T}=-0,323, \mathrm{p}=0,001$, correspondingly). IGFBP-1 and asymmetric dimethylarginine (ADMA) serum levels decrease and IGF-2 level increase correlated with EQ-5D VAS increase $(T=-0,245, p=0,040 ; T=-0,272, p=0,034 ; T=0,263$, $\mathrm{p}=0,034$, correspondingly).

\begin{tabular}{|l|l|c|c|c|}
\hline \multicolumn{2}{|c|}{ Variable } & EQ 5D sum<10, \% & EQ 5D sum> 10, \% & P $^{*}$ \\
\hline \multirow{2}{*}{$\begin{array}{l}\text { Medical observa- } \\
\text { tion }\end{array}$} & Yes & 75 & 25 & \multirow{2}{*}{0,015} \\
\cline { 2 - 5 } & No & 28,6 & 71,4 & \\
\hline \multirow{2}{*}{ Work } & Pensioner & 62,5 & 37,5 & 0,005 \\
\cline { 2 - 5 } Education & Works & 89,7 & 10,3 & \multirow{2}{*}{0,012} \\
\cline { 2 - 5 } & Higher & 86,2 & 13,8 & \\
\cline { 2 - 5 } & Secondary & 56,7 & 43,3 & \\
\end{tabular}
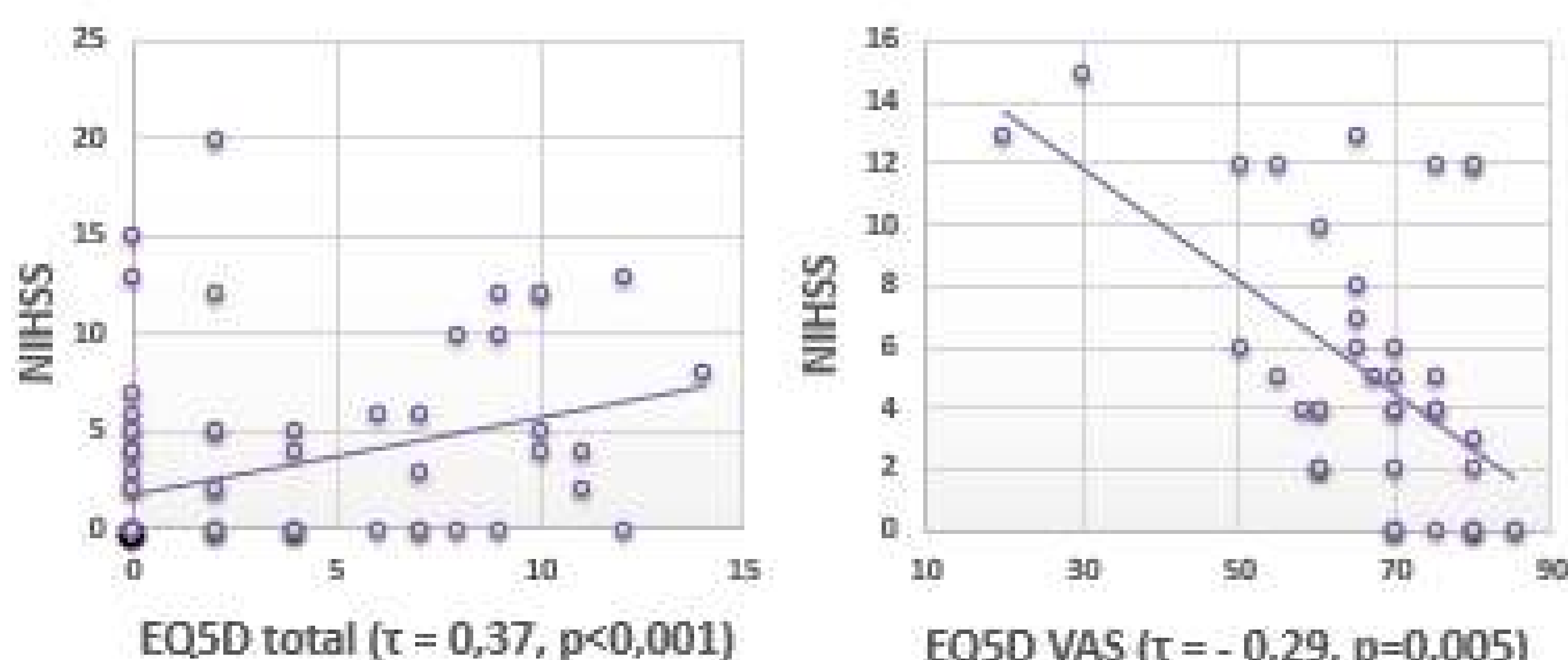

EQ5D total $(\tau=0,37, p<0,001)$

EQ50 VAS $(\tau=-0,29, p=0,005)$

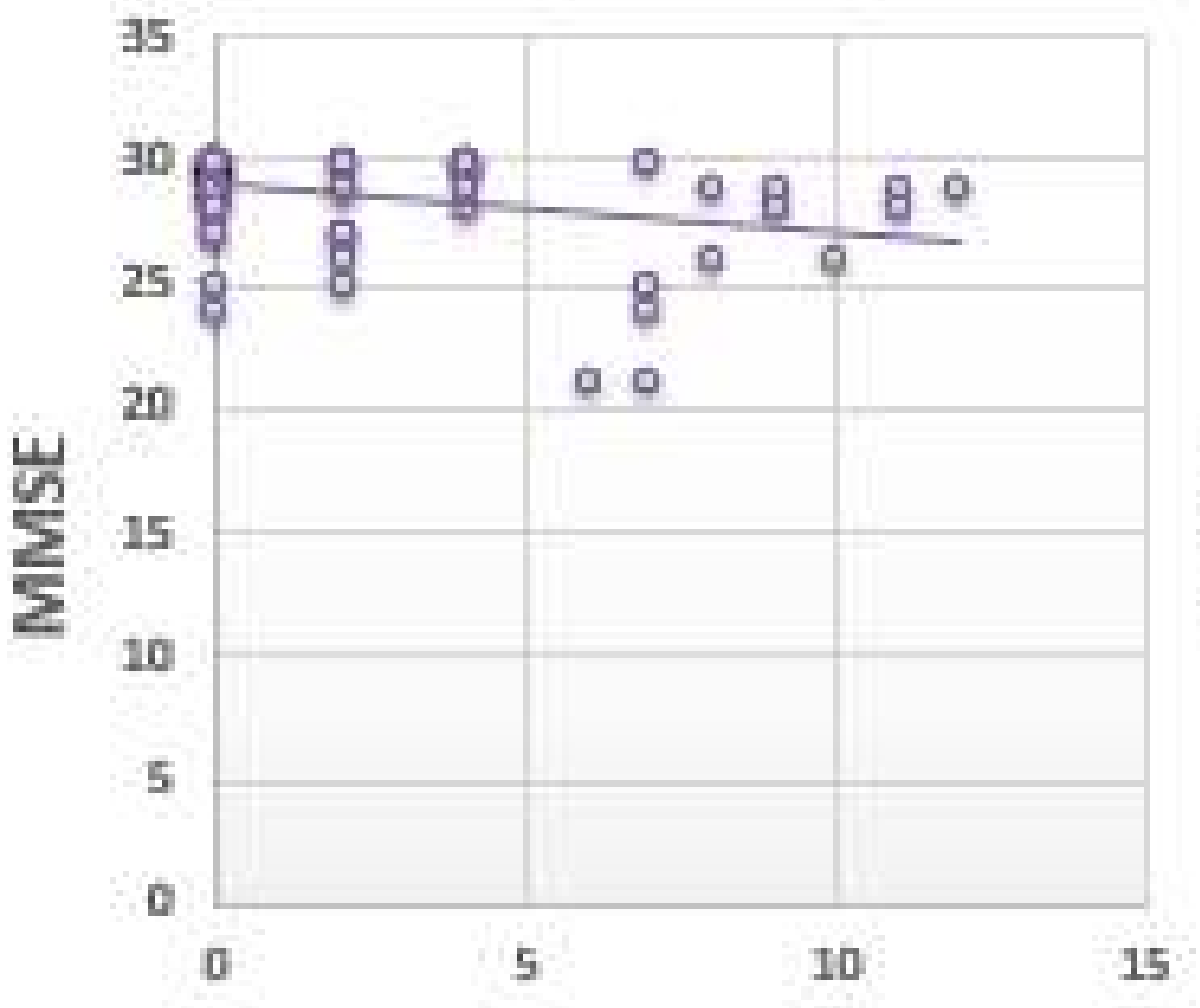

EQ5D total $(\tau=0,32, p=0,001)$

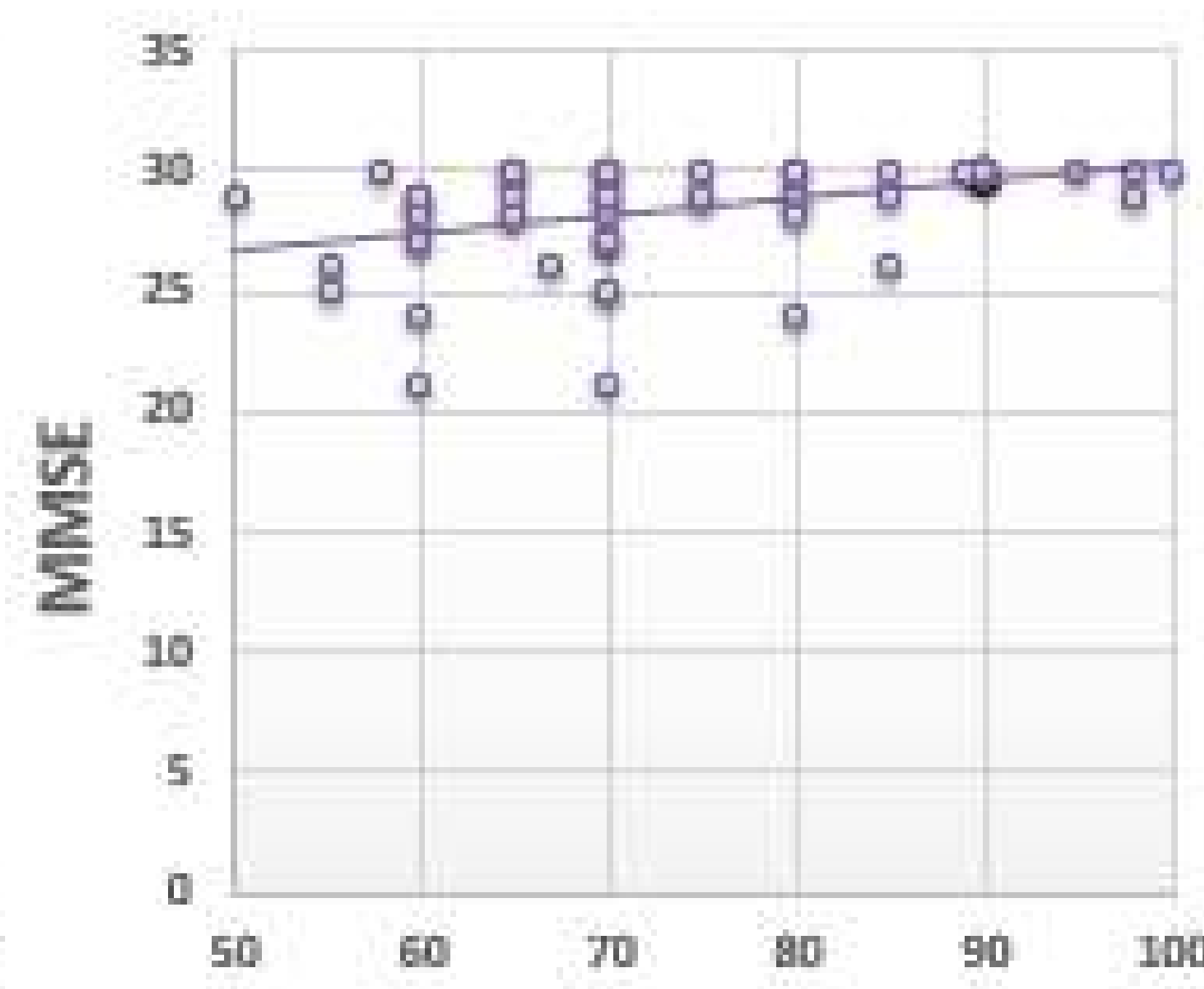

EQ 5D VAS $(\tau=0,422, p=0,001)$

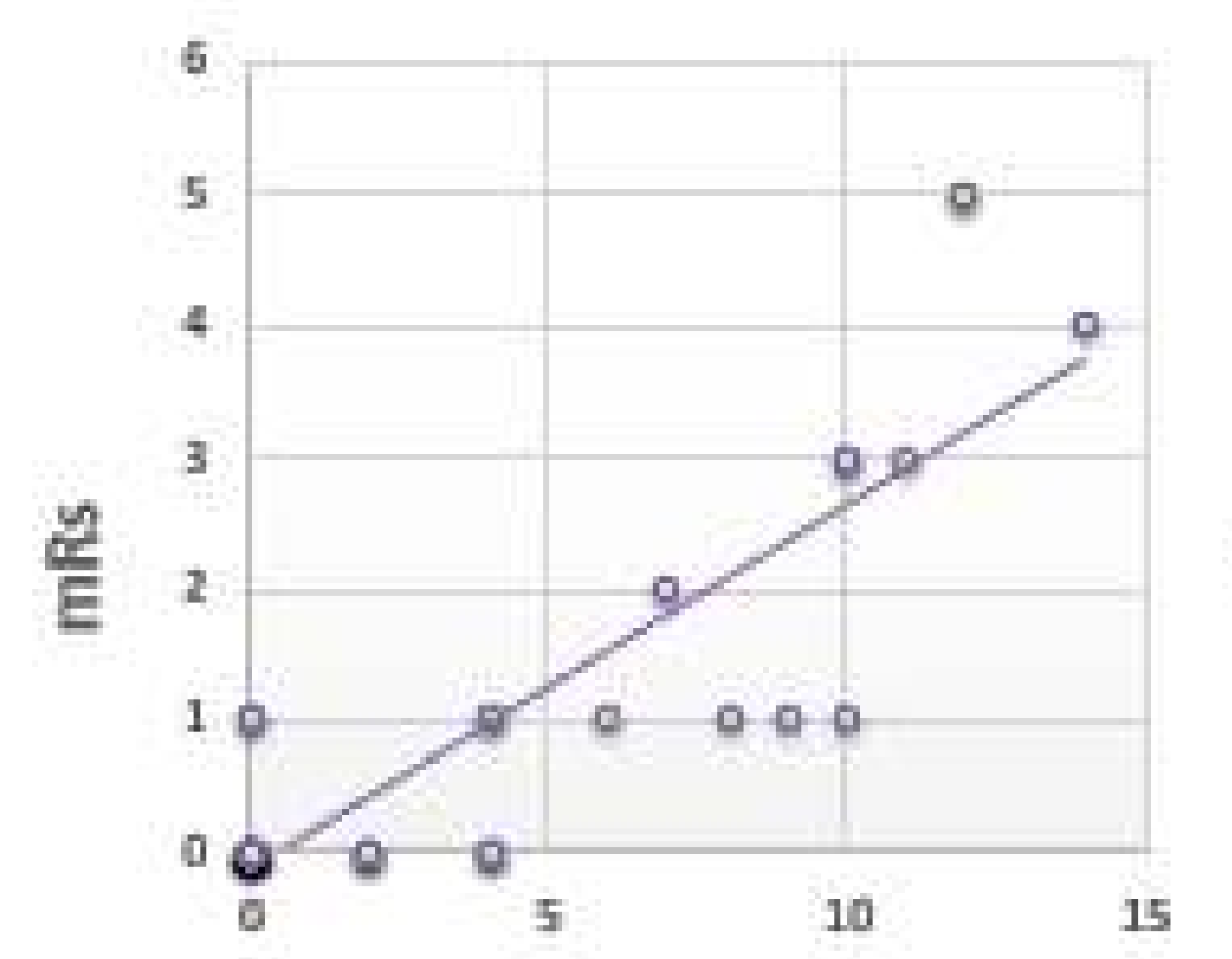

EQ 5D total $(\tau=0,63, p<0,001)$

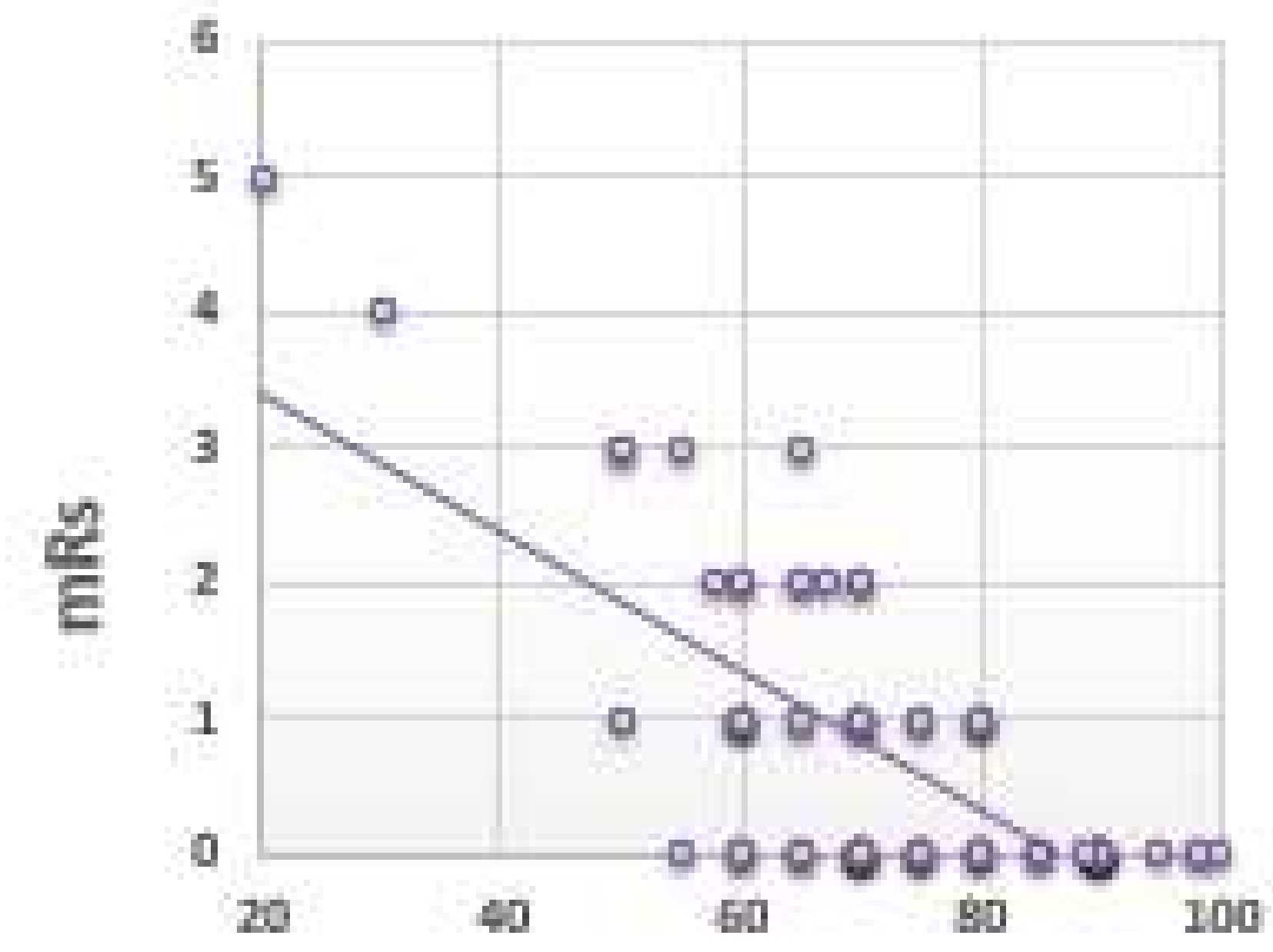

EQ 5D VAS $(\tau=-0,43, p<0,001)$
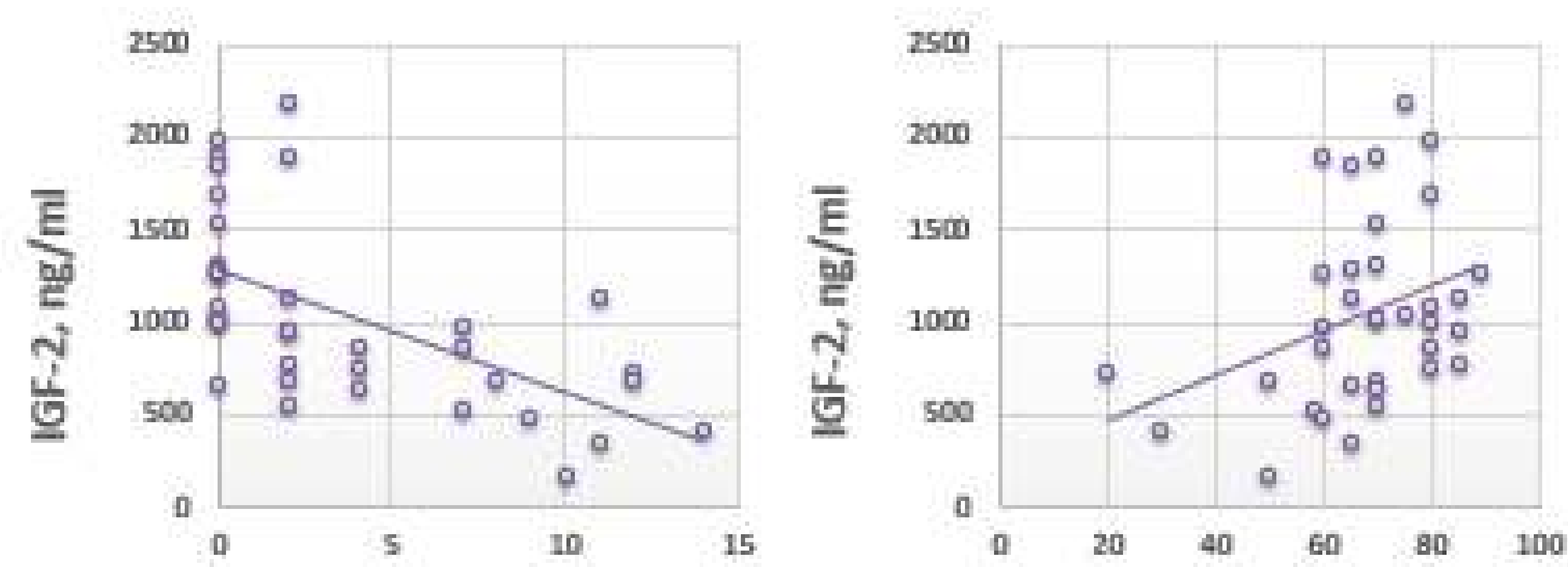

EQ5D total $(\tau=-0,52, p<0,001)$

EQ $5 D$ VAS $(\tau=0,26, p=0,034)$

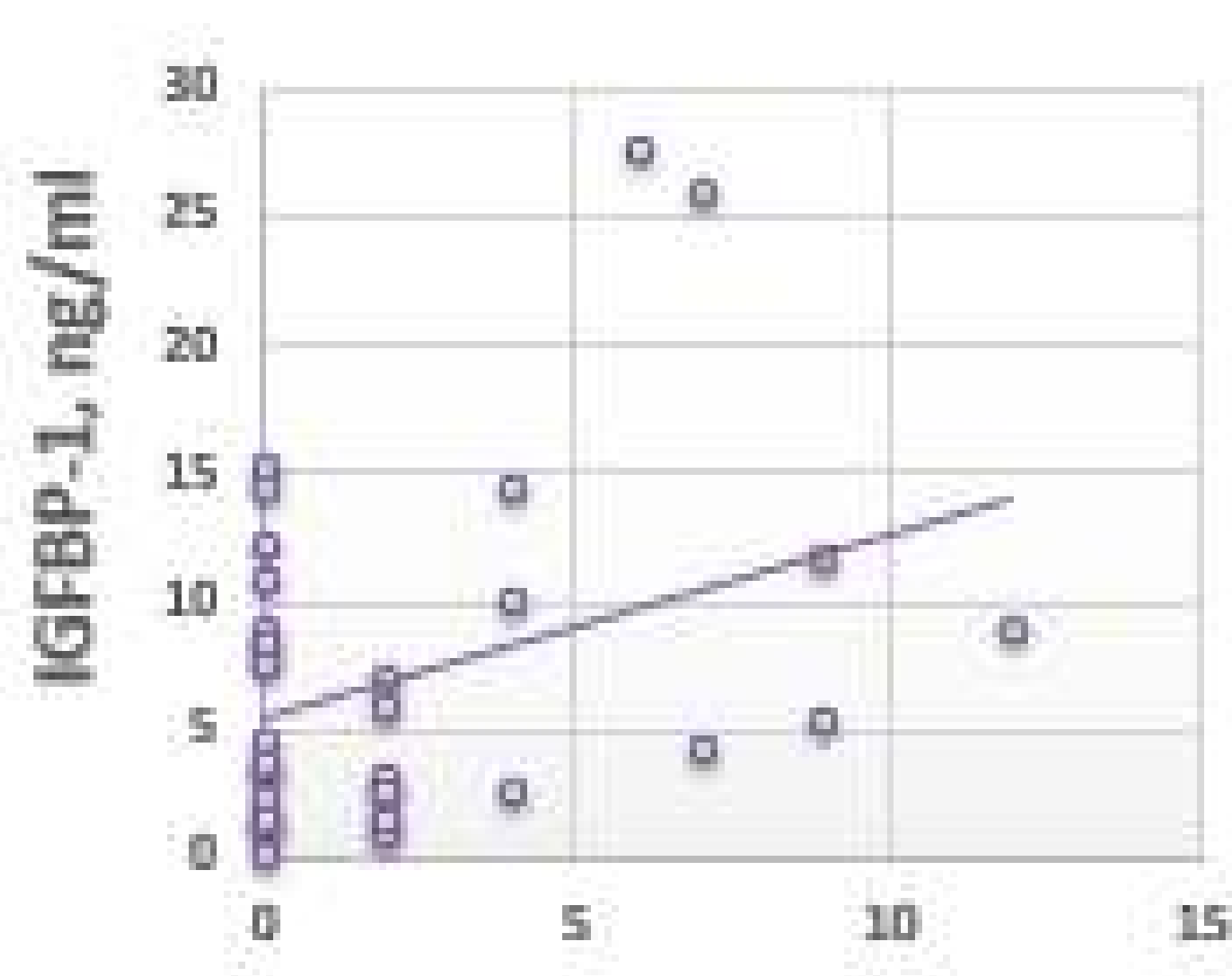

EQ5D total $(\mathrm{r}=0,31, \mathrm{p}=0,013)$

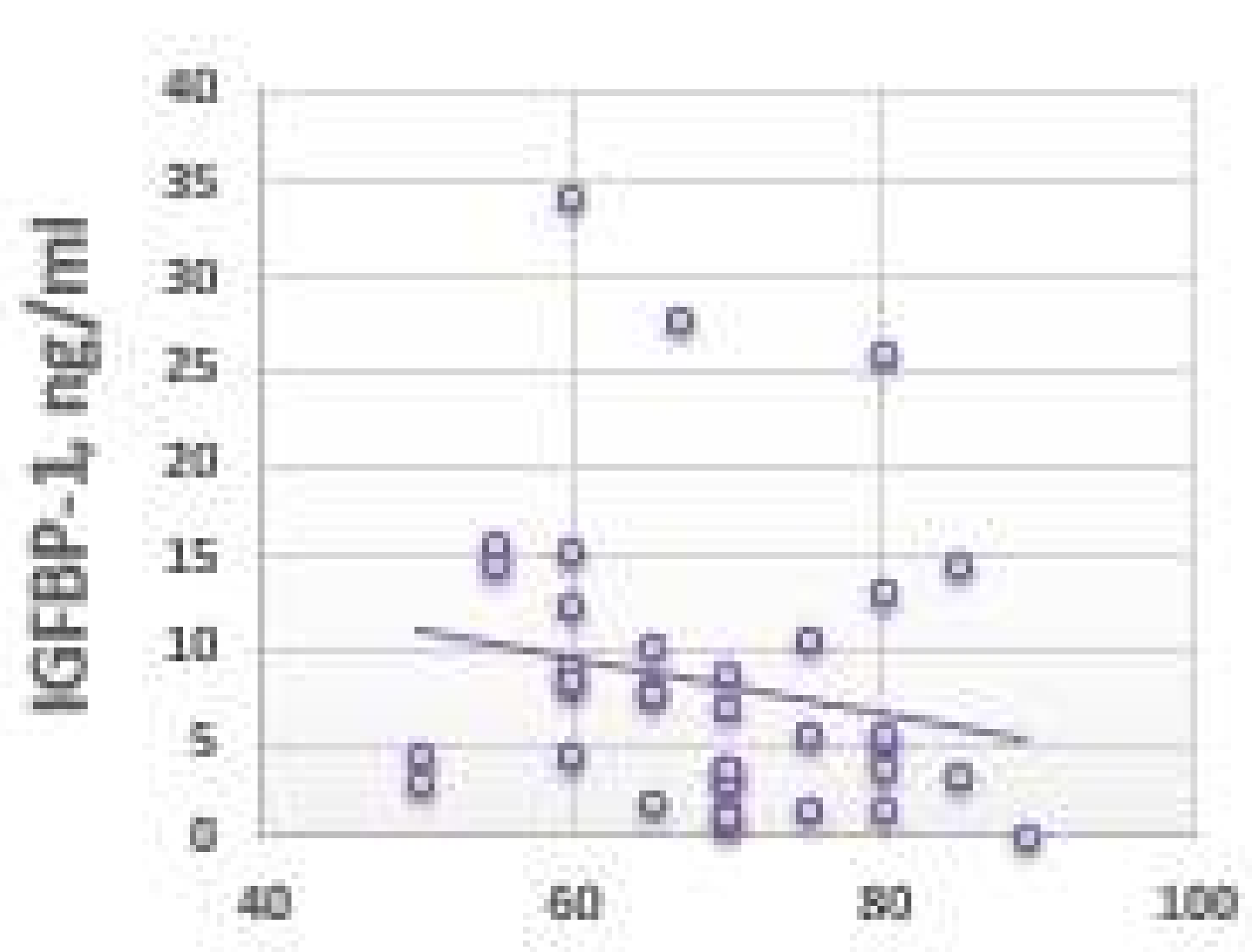

EQ 5D VAS $(\tau=0,311, p=0,013)$

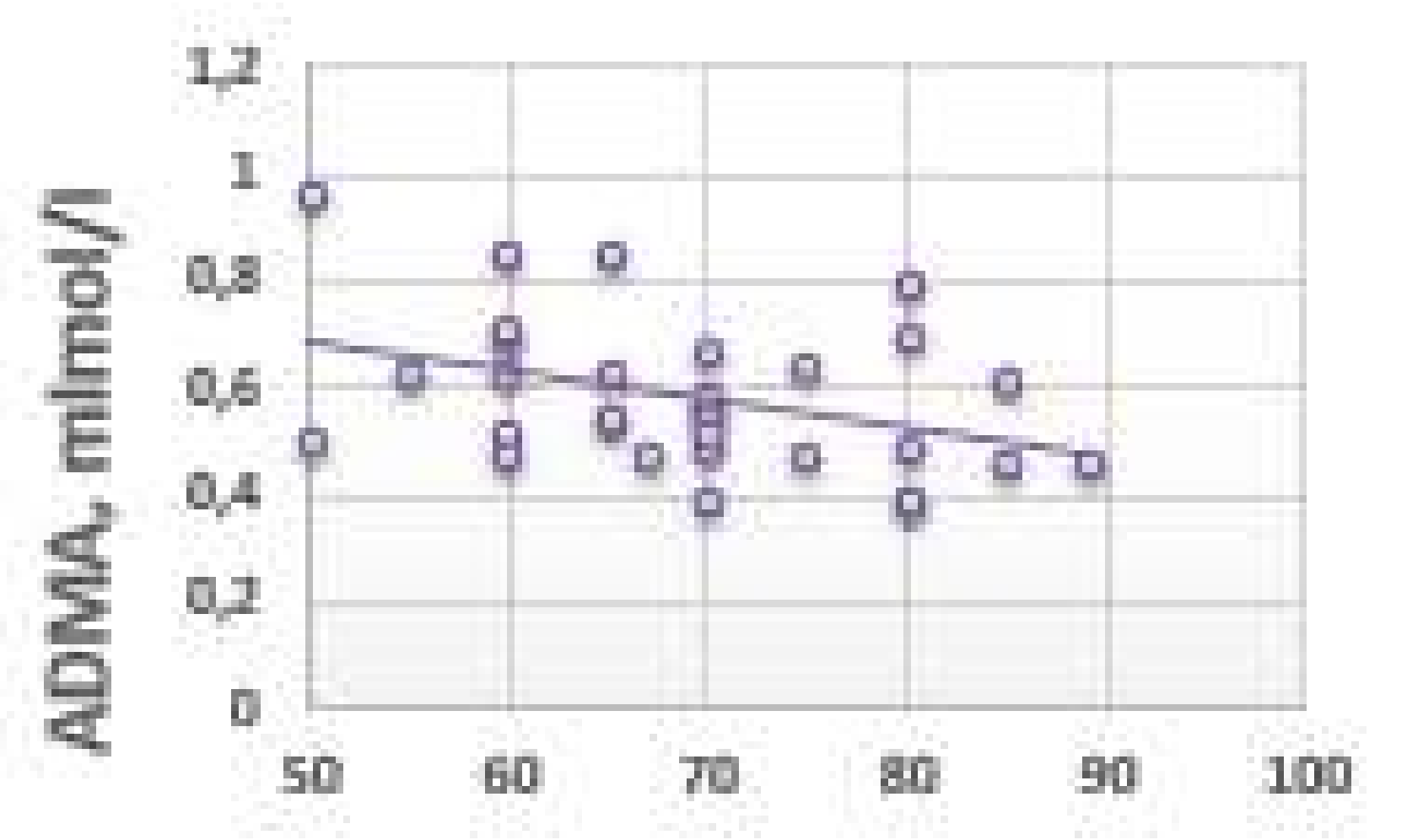

EQ 5D VAS $(\tau=-0,27, p=0,034)$

Conclusion

IGF family proteins serum activity inhibition and ADMA activation in patients with ACAS predict their poor health quality. Lower disability degree, stroke severity and cognitive impairment, presence of medical observation and work and higher education are positive health quality prognostic factors in these patients. 